\title{
Histopathological examination of thyroid specimens - a single center study from Peshawar, Khyber Pakhtunkhwa
}

\author{
Salman Khan, Muhammad Khizar Hayat, Omer Nasim, Muhammad Shah Fahad
}

\section{Submitted}

December 23, 2020

Accepted

January 18,2020

\section{Author Information}

Dr. Salman khan

Trainee, General Surgery, Hayatabad Medical Complex, Peshawar, Khyber

Pakhtunkhwa, Pakistan

Dr. Muhammad Khizar Hayat Lecturer, Community

Medicine, Rehman Medical

College, Peshawar, Khyber

Pakhtunkhwa, Pakistan

(Corresponding Author)

Email:

khizar.hayat-13@rmi.edu.pk

Dr. Omer Nasim

Trust Grade Doctor, Trauma \& Orthopedics, Poole Hospital/University Hospitals Dorset, UK

Dr. Muhammad Shah Fahad Trainee, General Surgery, Combined Military Hospital Peshawar, Khyber

Pakhtunkhwa, Pakistan

Citation: Khan S, Hayat MK, Nasim O, Fahad MS.

Histopathological

examination of thyroid specimens - a single center study from Peshawar, Khyber Pakhtunkhwa. J Rehman Med Inst. 2020 Jan-Mar;6(1):20-2.

\begin{abstract}
Introduction: Thyroid gland enlargement is a surgical problem that affects about a third of the world's adults Thyroid enlargement is best diagnosed by histopathology of surgical specimen and can also give a clue about different pattern of diseases that include simple goiter, multinodular goiter, thyroiditis, adenoma, and last but not the least, carcinoma.
\end{abstract}

Objective: To determine presentation of thyroid lesions based on their histopathology in patients presenting to Rehman Medical Institute (RMI), Peshawar from August 2018 to July 2019.

Materials \& Methods: This was a descriptive crosssectional study, inclusive of all thyroid specimens, irrespective of age and gender, received in the Department of Pathology, Rehman Medical Institute (RMI), Peshawar, from August 2018 to July 2019. Data were retrieved and analyzed for descriptive statistics in MS Excel.

Results: A total of 64 samples were collected; $56(87.5 \%)$ were non-neoplastic lesions while $08(12.5 \%)$ were neoplastic. 40(71\%) multi nodular goiters, $11(19.64 \%)$ simple nodular goiter, $01(1.7 \%)$ case of Hashimoto's thyroiditis, among neoplastic 04(50\%) were found to be papillary carcinoma and $02(25 \%)$ each were follicular and medullary carcinoma. Female to male ratio was $5: 3$ or $1.67: 1$ in neoplastic lesions.

Conclusion: The most common cause of goiter was multinodular goiter. Among the neoplastic lesions, follicular adenoma was the commonest, while papillary carcinoma was the most common malignant lesions.

Keywords: Multinodular goiter, follicular adenoma, Papillary carcinoma, Fine needle aspiration cytology.

The authors declared no conflict of interest. All authors contributed substantially to the planning of research, data collection, data analysis, and write-up of the article, and agreed to be accountable for all aspects of the work.

\section{INTRODUCTION}

Thyroid nodules are a common clinical problem. In contrast, thyroid cancer is rare. However, thyroid cancer is often seen as a lump in the neck or with a thyroid nodule. The physician should be able to distinguish between benign lesions, requiring only medical treatment, and malignant thyroid nodules, which require surgical treatment. In making this difference, several clinical factors must be considered, including patient age, gender, thyroid function status, history of irradiation exposure, family history, and thyroid conditions. None of these items, however, are reliable markers to predict that a particular nodule will have a malignant potential. Although many tests have been performed for thyroid nodule evaluation, scintigraphy, ultrasonography, and CT scan, none has the diagnostic accuracy as of thyroid fineneedle aspiration (FNA) biopsy.

Although the thyroid and nodule are common disorders, its prevalence depends on the apparent level of the method used for screening, and the population being screened. In general, thyroid tumors are more common in the elderly, in women, in iodine deficient regions, and in subjects that have already been exposed to irradiation of the head and neck.

Thyroid nodules that are larger than $1 \mathrm{~cm}$ can be palpated clinically. The prevalence though on palpation is a mere $4-7 \% .{ }^{1}$ Hence simple palpation even by experienced doctors, is not a very sensitive tool for diagnoses.

Ultrasound use for diagnosis has become the gold standard. When thyroid gland is examined by ultrasonography, the prevalence of thyroid tumors increases dramatically, estimates range from 10 to $41 \%$. $^{2}$ Some studies have also stated incidental findings of thyroid nodules on ultrasonography to be $50-67 \%{ }^{3}$

Although gender is not an independent prognostic factor for thyroid cancer, men usually have a far more advanced disease as compared to women. ${ }^{4}$ Previous radiation exposure though has a significant relation, thirty percent $(30 \%)$ of patients who have previous history of radiation, develop palpable nodules and have a bad clinical outcome. $^{5}$ 
Although these clinical features may suggest that the nodule may be malignant, but many patients without these symptoms are diagnosed with thyroid cancer on further evaluation. Of all currently available thyroid nodule diagnoses, FNA biopsy has been found to have the highest diagnostic accuracy, approaching 95\%. ${ }^{6}$ It is a safe and inexpensive process, with little or no complications. Most of the cytologic findings of FNA are diagnostic giving it a sensitivity, specificity and accuracy of $91.6 \%, 100 \%$ and $97 \%$ respectively, according to a study conducted in $2011 .^{7}$

A positive or malignant cytology suggest the presence of malignancy, either primary or metastatic cancer. Among all thyroid carcinoma, papillary carcinoma is most common thyroid malignancy. ${ }^{8}$ Neoplasm of follicular or Hurtle cell cannot differentiated into benign or malignant subtypes on the basis of cytologic findings only. ${ }^{9}$ The outcome of a biopsy also depends upon the experience of the person taking the aspiration, as well as the nature of lesions, for example if specimen contain too much blood or cystic fluid and few or no thyroid cells the outcome can be non-diagnostic or unsatisfactory. ${ }^{10}$

This study aimed to determine the presentation of thyroid diseases based on their histopathology in patients undergoing interventional procedures at Rehman Medical Institute (RMI) since a baseline for such diseases is not present. This will help surgeons widen their differentials if an uncommon diagnosis is seen to be presenting more in Peshawar.

\section{MATERIALS \& METHODS}

A descriptive, cross-sectional study conducted at the Rehman Medical Institute (RMI) histopathology unit. Data were acquired for the duration August 2018 till July 2019. All thyroid specimens sent for histopathology regardless of age were included in the study. These included specimens that were surgically resected or ultrasound guidance-based excision by the interventional radiology department. Any specimens that had deficient data were disregarded. Data retrieved from the histopathology unit was in a Microsoft Excel file. It included age, gender, diagnosis, and specimen type. This data was then analyzed using Microsoft Excel for descriptive statistics and pivot tables were generated.

\section{RESULTS}

A total of 64 samples were collected from the patient's thyroid through surgical resection and through ultrasound guided resection by interventional radiology, from August $1^{\text {st }}, 2018$ till July $31^{\text {st }}, 2019$. The mean age of the patients was $42.73 \pm 14$ (SD). Majority $81.25 \%$ were female while $18.75 \%$ were male. The most common abnormality was multinodular goitre comprising $40(62.5 \%)$, followed by nodular goitre $11(17.18 \%)$ and papillary cancer $04(6.25 \%)$. Patients in the age bracket of 0-20 year had 03 cases (4.68\%), 21-40 years had 26 cases (40.6\%), 41-60 years had 29 cases (45.3\%) and above 60 years had 06 cases $(9.37 \%)$. In the female the most common thyroid abnormality was multinodular goitre, followed by nodular goitre and papillary carcinoma; comprising of 50\%, $15.6 \%$ and $4.68 \%$ respectively. In the male the most common abnormality detected through FNA was multinodular goitre and medullary carcinoma; comprising of $12.5 \%$ and $3.12 \%$ respectively. The thyroid abnormalities were most common in the 41-60 age group $[29(45.3 \%)]$ followed by the $21-40$ age group [26(40.6\%)] (Table. 1).

Table 1: Male and female age distribution, age brackets and FNAC results $(n=64)$.

\begin{tabular}{|c|c|c|c|c|c|c|c|}
\hline \multirow[t]{2}{*}{ FNAC Results } & \multirow{2}{*}{$\begin{array}{l}\text { Frequency } \\
\quad \text { n }(\%)\end{array}$} & \multicolumn{4}{|c|}{$\begin{array}{c}\text { Age Brackets (years) } \\
\text { n }(\%)\end{array}$} & \multicolumn{2}{|c|}{ Gender } \\
\hline & & $\mathbf{0 - 2 0}$ & $21-40$ & 41-60 & $60+$ & Male & Female \\
\hline Multinodular Goiter & $40(62.5)$ & . & $18(28.1)$ & $17(26.6)$ & $5(7.81)$ & $8(12.5)$ & $32(50.0)$ \\
\hline Nodular Goiter & $11(17.1)$ & $2(3.13)$ & $3(4.68)$ & $6(9.38)$ & . & $1(1.56)$ & $10(15.6)$ \\
\hline Follicular $\mathrm{Ca}$ & $2(3.13)$ & . & $1(1.56)$ & $1(1.56)$ & . & . & $2(3.13)$ \\
\hline Follicular Adenoma & $1(1.56)$ & $1(1.56)$ & . & 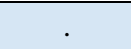 & . & . & $1(1.56)$ \\
\hline Chronic Thyroiditis & $1(1.56)$ & . & . & $1(1.56)$ & . & . & $1(1.56)$ \\
\hline Papillary $\mathrm{Ca}$ & $4(6.25)$ & . & $3(4.68)$ & $1(1.56)$ & . & $1(1.56)$ & $3(4.68)$ \\
\hline Normal & $1(1.56)$ & . & . & $1(1.56)$ & . & . & $1(1.56)$ \\
\hline Medullary $\mathrm{Ca}$ & $2(3.13)$ & . & . & $1(1.56)$ & $1(1.56)$ & $2(3.13)$ & . \\
\hline Colloid Cyst & $1(1.56)$ & . & . & $1(1.56)$ & . & . & $1(1.56)$ \\
\hline Hashimoto Thyroiditis & $1(1.56)$ & . & $1(1.56)$ & & . & . & $1(1.56)$ \\
\hline
\end{tabular}

\section{DISCUSSION}

The enlargement of the thyroid gland is surgical problem affects about a third of the world's adults. ${ }^{11}$ thyroid malignancy is often diagnosed after operation and sending specimen for histopathology. There is general consideration that patients having multinodular goiter are at lower risk of malignancy than nodule alone. However, literature reviews have shown that the rate of malignant tumors in patients with single nodule is not significantly different from those with multinodular goiter. ${ }^{12}$
Variations in thyroid carcinoma have been observed in different parts of the world.

The total incidence of non-neoplastic lesions in this study was $87.5 \%$ compared $12.5 \%$ of neoplastic lesions. Supported by other studies done in Pakistan. ${ }^{13,14}$ The most common nonneoplastic conditions in this study were multinodular goiters and nodular goiter $71.4 \% \%$ and $19.64 \%$ respectively. These 
results are consistent with studies previously done in which nodular and multinodular goiter were most frequent findings. ${ }^{15-}$ 17

As far as various forms of inflammatory condition of the thyroid gland are concerned, around $2 \%$ of patients had thyroiditis, as seen in some studies. ${ }^{16,18}$

In this study, Papillary Carcinoma was the most common thyroid malignancy seen in about 50\% (4/8) of specimens; this finding is consistent with several other studies. ${ }^{19,20}$

\section{CONCLUSION}

Though statistics of thyroid malignancy among other thyroid nodule are low but the nature and characteristic of thyroid nodule should not be underestimated, and each nodule should be examined and further evaluated through FNAC to rule out malignancy.

\section{REFERENCES}

1. Bomeli SR, LeBeau SO, Ferris RL. Evaluation of a thyroid nodule. Otolaryngol Clin North Am. 2010;43(2):229-38.

2. Shayeb MA, Varma SR, Kaseh AE, Ashekhi A, Kuduruthullah S, Khader IE. Incidental thyroid nodules on ultrasound screening of the neck region: prevalence \& risk factors. Clinical Practice. 2018;15(5):873-9.

3. Moifo B, Tapouh JRM, Fomekong SD, Djomou F, Wankie EM. Ultrasonographic prevalence and characteristics of nonpalpable thyroid incidentalomas in a hospital-based population in a sub-Saharan country. BMC Med Imaging. 2017;17:21.

4. Nilubol N, Zhang L, Kebebew E. Multivariate analysis of the relationship between male sex, disease-specific survival, and features of tumor aggressiveness in thyroid cancer of follicular cell origin. Thyroid. 2013;23(6):695-702.

5. Seaberg RM, Eski S, Freeman JL. Influence of previous radiation exposure on pathologic features and clinical outcome in patients with thyroid cancer. Arch Otolaryngol Head Neck Surg. 2009;135(4):355-9.

6. Halenka M, Fryšák Z. Ultrasound-Guided Fine-Needle Aspiration Biopsy (US-
FNAB). Atlas of $\quad$ Thyroid
Ultrasonography. $2017 ;: 383-92$.

Esmaili HA, Taghipour H. Fine-Needle Aspiration in the Diagnosis of Thyroid Diseases: An Appraisal in Our Institution. ISRN Pathology. 2012;2012:1-4.

8. Kim WB. A Closer Look at Papillary Thyroid Carcinoma. Endocrinology and Metabolism. 2015;30(1):1.

9. Gharib H, Goellner JR, Johnson DA. Fineneedle aspiration cytology of the thyroid: a 12-year experience with 11,000 biopsies. Clin Lab Med 1993 Sep; 13:699-709.

10. Kim MW, Kim DW, Jung HS, Choo HJ, Park YM, Jung SJ, et al. Factors influencing the outcome of ultrasoundguided fine-needle aspiration for salivary gland lesion diagnosis. J Ultrasound Med. 2016;35(5):877-83.

11. Vanderpump MPJ. The epidemiology of thyroid disease. British Medical Bulletin. 2011;99(1):39-51.

12. Tsegaye B, Ergete W. Histopathological pattern of thyroid disease. East Afr Med J 2003; 80:525-8.

13. Hussain N, Anwar. M, Nadia N, Ali Z. Pattern of surgically treated thyroid diseases in Karachi. Biomedica. 2005;21:18-20.
14. Akhtar S, Khan AZ, Ahmed M, Osman L, Ahmed F, Chaudhry AM. Correlation of clinical presentation with investigations and operative findings in solitary nodule thyroid. Ann King Edward Med Coll 2001;7:158-61.

15. Elahi S, Manzoor-ul-Hassan A, Syed Z, Nazeer L, Nagra SA, Hyder SW. A study of goiter among female adolescents referred to centre for nuclear medicine, Lahore. Pak J Med Sci 2005;21:56-61.

16. Niazi S, Arshad M, Muneer M. A histopathological audit of thyroid surgical specimens. Ann King Edward Med Coll 2007;13:51-6

17. Imran AA, Majid A, Khan SA. Diagnosis of Enlarged thyroid-an analysis of 250 cases. Ann King Edward Med Coll 2005;11:203-4.

18. Qureshi N, Jaffar R, Ahmed N, Nagi WA Causes of goiter. A morphological analysis. Biomedical 1996;12:54-6.

19. Hussain N, Anwar. M, Nadia N, Ali Z. Pattern of surgically treated thyroid diseases in Karachi. Biomedica. 2005;21:18-20.

20. Khan AZ, Naqi SA, Kamal A, Abaid KJ. Thyroidectomy in carcinoma thyroid-a three years experience. Ann King Edward Med Coll. 2004;10:368-9. 